\title{
Genetic Diversity and Structure of Tropical Porites lutea Populations Highlight Their High Adaptive Potential to Environmental Changes in the South China Sea
}

OPEN ACCESS

Edited by:

lliana B. Baums,

The Pennsylvania State University,

United States

Reviewed by:

Carolina Bastidas,

Massachusetts Institute

of Technology, United States

Yuan Li,

Third Institute of Oceanography, Ministry of Natural Resources, China

${ }^{*}$ Correspondence:

Kefu Yu

kefuyu@scsio.ac.cn

${ }^{\dagger}$ These authors have contributed equally to this work

Specialty section:

This article was submitted to

Marine Science,

a section of the journal

Frontiers in Marine Science

Received: 08 October 2021

Accepted: 25 January 2022

Published: 28 February 2022

Citation:

Luo Y, Huang W, YU K, Li M,

Chen B, Huang X and Qin Z (2022)

Genetic Diversity and Structure

of Tropical Porites lutea Populations

Highlight Their High Adaptive

Potential to Environmental Changes

in the South China Sea.

Front. Mar. Sci. 9:791149.

doi: 10.3389/fmars.2022.791149

\section{Yanqiu Luo't, Wen Huang ${ }^{1 \dagger}$, Kefu Yu ${ }^{1,2 *}$, Ming Li' ${ }^{1}$, Biao Chen ${ }^{1}$, Xueyong Huang ${ }^{1}$ and Zhenjun Qin ${ }^{1}$}

${ }^{1}$ Guangxi Laboratory on the Study of Coral Reefs in the South China Sea, Coral Reef Research Center of China, School of Marine Sciences, Guangxi University, Nanning, China, ${ }^{2}$ Southern Marine Science and Engineering Guangdong Laboratory, Zhuhai, China

Global climate change and anthropogenic disturbance have significantly degraded biodiversity in coral reef ecosystems. The genetic potential and adaptability of corals are key factors used to predict the fate of global coral reefs under climate change. In this study, we used eight microsatellite loci to study the patterns of reproduction, genetic diversity, and genetic structure of 302 Porites lutea samples across $13^{\circ}$ latitudes in the South China Sea $\left(8.8644^{\circ} \mathrm{N}-22.6117^{\circ} \mathrm{N}\right)$. The results indicated that $P$. lutea reproduces largely via sexual reproduction on scales of $5 \mathrm{~m}$ and greater and has abundant gene diversity. Additionally, the tropical populations harbored high genetic diversity (based on alleles, effective number of alleles, gene diversity, and heterozygosity). In contrast, genetic diversity was lower in subtropical coral populations. Genetic variation values and pairwise $F_{S T}$ revealed that tropical and subtropical populations had significantly different genetic structures. Finally, the Mantel tests showed that the genetic differentiation and genetic variation of $P$. lutea were strongly correlated with sea surface temperature and slightly correlated with geographical distance. These results indicated that tropical $P$. lutea populations have high genetic potential and adaptability because of their sexual reproduction and genetic diversity, giving them a greater capacity to cope with climate change. Subtropical coral populations showed lower genetic diversity and, thus, relatively poor genetic resilience in response to low average sea surface temperature and human activities. Our study provides a theoretical basis for the protection and restoration of coral reefs.

Keywords: Porites lutea, genetic potential, genetic diversity, genetic structure, sea surface temperature, climate change

\section{INTRODUCTION}

Global warming has greatly decreased biodiversity and poses a critical threat to the health of coral reef ecosystems (Hughes et al., 2017; Thomas et al., 2017). The rising sea surface temperature (SST) causes a breakdown in the symbiotic associations between the coral host and its endosymbiotic dinoflagellate, resulting in coral bleaching (Chen et al., 2018). For instance, the record temperatures 
reported during 2015-2016 triggered a pan-tropical episode of coral bleaching (Hughes et al., 2017). An important factor in coral recovery from environmental stress is its genetic potential (Williams et al., 2014), or the ability of a population to evolve under changing selection pressures (Meyers et al., 2005). Genetic diversity was regarded as the fundamental evolutionary source in speciation and adaptation, reflecting the level of population genetic potential and adaptability. As a population's genetic diversity increases, so does its genetic potential (Barrett and Schluter, 2008; Hoegh-Guldberg and Bruno, 2010; Thomas et al., 2017). With increases in environmental stressors such as eutrophication, habitat fragmentation, and climate change, the genetic diversity of keystone species may become increasingly important (Hughes and Stachowicz, 2004). The sea surface temperature, ocean currents, breeding patterns, and geographical distances were the most reported factors affecting genetic characteristics of corals in some coral reefs (Knittweis et al., 2009; Tye et al., 2013; Mclachlan et al., 2020). In Western Australia, the low latitude coral populations had higher genetic potential than the high latitude coral populations. The corals in high latitudes were more vulnerable than corals in tropical areas to cope with global climate change (Ayre and Hughes, 2004; Miller and Ayre, 2010; Thomas et al., 2017). Genetic diversity is considered to enhance the sustainability of populations over evolutionary time scales by furnishing sufficient alleles for future environment changes (Ayre and Hughes, 2004; Williams et al., 2014).

The coral reefs of the South China Sea (SCS) are on the northern edge of the Coral Triangle region and comprise high diversity and abundant biological resources (Yu, 2012). The SCS contains both tropical and subtropical coral reefs (Yu, 2012), with distinct SSTs linked to latitudinal gradients (Chen et al., 2019; Qin et al., 2019). However, the genetic characteristics of corals have barely been investigated in the SCS. Recently, Wu et al. (2021) reported low genetic diversity and moderate genetic differentiation of the dominant coral Turbinaria peltata at relatively high latitudes in the SCS. The genetic structure was significantly affected by the average SST, geographical isolation, and anthropogenic activities. Huang et al. (2018) reported high genetic diversity and connectivity in P. lutea across the SCS based on nuclear markers (internal transcribed spacer and $\beta$-tubulin). However, no evident genetic structure or effecting factors were found. The genetic characteristics of Mycedium elephantotus, Platygyra sinensis, and Platygyra verweyi in the north SCS also have no obvious genetic structure (Yu et al., 1999; Ng and Morton, 2003; Keshavmurthy et al., 2012). The limited genetic information and limited number of species investigated in this area has hampered the formulation of coral reef protection measures.

Porites lutea is widely distributed in the subtropical and tropical regions of the SCS. This coral species is considered to be adaptable to climate change and other forms of anthropogenic disturbance (Xu et al., 2017; Qin et al., 2019). The species contains a high density of heat-tolerant symbiotic zooxanthellae C15 and a rich diversity of symbiotic microorganisms (Liang et al., 2017; Chen et al., 2020). In this study, we investigated the genetics of $P$. lutea from coral reef sites in the SCS spanning $13^{\circ}$ latitudes based on eight microsatellite loci. We focused on (1) the relationship between genetic potential and reproduction patterns and genetic diversity, (2) how genetic structure varies across latitudes, (3) the relationship between $P$. lutea genetic structure and SST in the SCS, and (4) the genetic potential and adaptability of $P$. lutea populations in tropical areas.

\section{MATERIALS AND METHODS}

\section{Sample Collection}

Fragments $\left(\sim 2-3 \mathrm{~cm}^{2}, n=302\right)$ of $P$. lutea were collected from 14 different coral reef sites in the SCS, covering a wide range of latitudes $\left(8.8644^{\circ} \mathrm{N}\right.$ to $\left.22.6117^{\circ} \mathrm{N}\right)$ : Xiaolajia and Yangmeikeng in Daya Bay; one site in Weizhou Island; one site-Luhuitou in Sanya Bay; Beijiao, Qilianyu, Yongxing, Dongdao, Yuzhuo, and Langhua in the Xisha Islands; and Huangyan in Zhongsha Islands; Sanjiaojiao, Xinyijiao, and Dongjiao in the Nansha Islands (Table 1 and Figure 1). We identified $P$. lutea based on morphological characteristics. In addition, the collected samples of $P$. lutea were confirmed by ITS in our previous study (Huang et al., 2018). Furthermore, many studies showed that $P$. lutea is widely distributed in the SCS (Yu, 2012; Huang et al., 2021). Fragments were obtained at depths of 4-10 $\mathrm{m}$. Sampled colonies were separated by at least $5 \mathrm{~m}$ to minimize the probability of collecting samples from the same ramet more than once (Magalon et al., 2005). Small fragments were broken from colonies using a hammer and chisel, and then stored in 95\% ethanol or at $-80^{\circ} \mathrm{C}$ until DNA extraction. Genomic DNA was extracted using a marine animal tissue genomic DNA extraction kit (Tiangen Biotech, Beijing, China) following the manufacturer's protocol.

\section{PCR Amplification and Sequencing}

Microsatellite markers can be used to study the genetics of different species of the same genus (Magalon et al., 2004; Severance et al., 2010). Eight microsatellite loci from P. lobata were validated for the analysis of $P$. lutea in this study. Primers PL0340, PL1556, PL2258, and PL0780 were from Polato et al. (2010), and primers PL1370, PL0905, PL1483, and PL1868 were from Baums et al. (2012). The forward primer of PL0340, PL2258, PL0780, PL0905, PL1968 was fluorescently labeled with 6FAM. The forward primer of PL1556, PL1370, PL1483 was fluorescently labeled with HEX. The PCR was performed with $50 \mathrm{ng}$ template DNA, $0.4 \mu \mathrm{L}$ forward primer, $0.4 \mu \mathrm{L}$ reverse primer, $10 \mu \mathrm{L} 2 \times$ PCR enzyme mix (Tiangen Biotech) and Tiangen-free water to the total volume of $20 \mu \mathrm{L}$. Thermocycling (ABI GeneAmp ${ }^{\circledR}$ 9700) was performed as follows: $94^{\circ} \mathrm{C}$ for $3 \mathrm{~min}, 40$ cycles at $94^{\circ} \mathrm{C}$ for $30 \mathrm{~s}$, annealing temperature for $30 \mathrm{~s}, 72^{\circ} \mathrm{C}$ for $45 \mathrm{~s}$, and $72^{\circ} \mathrm{C}$ for $5 \mathrm{~min}$. Fragments were analyzed using capillary electrophoresis, on an ABI 3730 sequencer with an internal size standard Genescan LIZ 500 (Applied Biosystems). Electropherograms were visualized, and allele sizes were calculated in GENEMAPPER 4.0. Each marker 
TABLE 1 | Porites lutea samples were collected from 14 coral reef sites in the South China Sea.

\begin{tabular}{|c|c|c|c|c|c|c|c|c|}
\hline Region & Site & Reef type & Sampling dates & $N$ & $N g$ & $N g / N$ & Latitude & Longitude \\
\hline \multirow[t]{2}{*}{ Daya Bay } & Xiaolajia & Subtropical non-reefal & 2018.05 & 18 & 18 & 1.00 & $22.6117^{\circ}$ & $114.6311^{\circ}$ \\
\hline & Yangmeikeng & Subtropical non-reefal & 2018.05 & 21 & 21 & 1.00 & $22.5492^{\circ}$ & $114.5694^{\circ}$ \\
\hline Weizhou Island & Weizhou & Subtropical reefal & 2015.08 & 20 & 20 & 1.00 & $21.0204^{\circ}$ & $109.0805^{\circ}$ \\
\hline Sanya Bay & Luhuitou & Tropical reefal & 2015.08 & 20 & 20 & 1.00 & $18.2176^{\circ}$ & $109.4855^{\circ}$ \\
\hline \multirow[t]{6}{*}{ Xisha Islands } & Beijiao & Tropical reefal & 2015.08 & 19 & 19 & 1.00 & $17.1033^{\circ}$ & $111.4830^{\circ}$ \\
\hline & Qilianyu & Tropical reefal & 2015.08 & 23 & 23 & 1.00 & $16.9703^{\circ}$ & $112.3142^{\circ}$ \\
\hline & Yongxing & Tropical reefal & 2015.08 & 24 & 24 & 1.00 & $16.8476^{\circ}$ & $112.3588^{\circ}$ \\
\hline & Dongdao & Tropical reefal & 2015.08 & 23 & 23 & 1.00 & $16.6748^{\circ}$ & $112.7375^{\circ}$ \\
\hline & Yuzhuo & Tropical reefal & 2015.08 & 23 & 23 & 1.00 & $16.3638^{\circ}$ & $112.0168^{\circ}$ \\
\hline & Langhua & Tropical reefal & 2015.08 & 20 & 20 & 1.00 & $16.0845^{\circ}$ & $112.5921^{\circ}$ \\
\hline Zhongsha Islands & Huangyan & Tropical reefal & 2015.08 & 23 & 23 & 1.00 & $15.2190^{\circ}$ & $117.7477^{\circ}$ \\
\hline \multirow[t]{3}{*}{ Nansha Islands } & Sanjiaojiao & Tropical reefal & 2016.08 & 24 & 24 & 1.00 & $10.1899^{\circ}$ & $115.2967^{\circ}$ \\
\hline & Xinyijiao & Tropical reefal & 2016.08 & 22 & 22 & 1.00 & $9.3281^{\circ}$ & $115.9332^{\circ}$ \\
\hline & Dongjiao & Tropical reefal & 2018.06 & 22 & 21 & 0.95 & $8.8644^{\circ}$ & $112.8300^{\circ}$ \\
\hline \multirow[t]{2}{*}{ Total } & & & & 302 & 301 & & & \\
\hline & & & & 21.57 & 21.50 & 0.99 & & \\
\hline SD & & & & 1.84 & 1.84 & 0.13 & & \\
\hline
\end{tabular}

Sample size $(\mathrm{N})$, number of unique multilocus genotypes $(\mathrm{Ng})$.

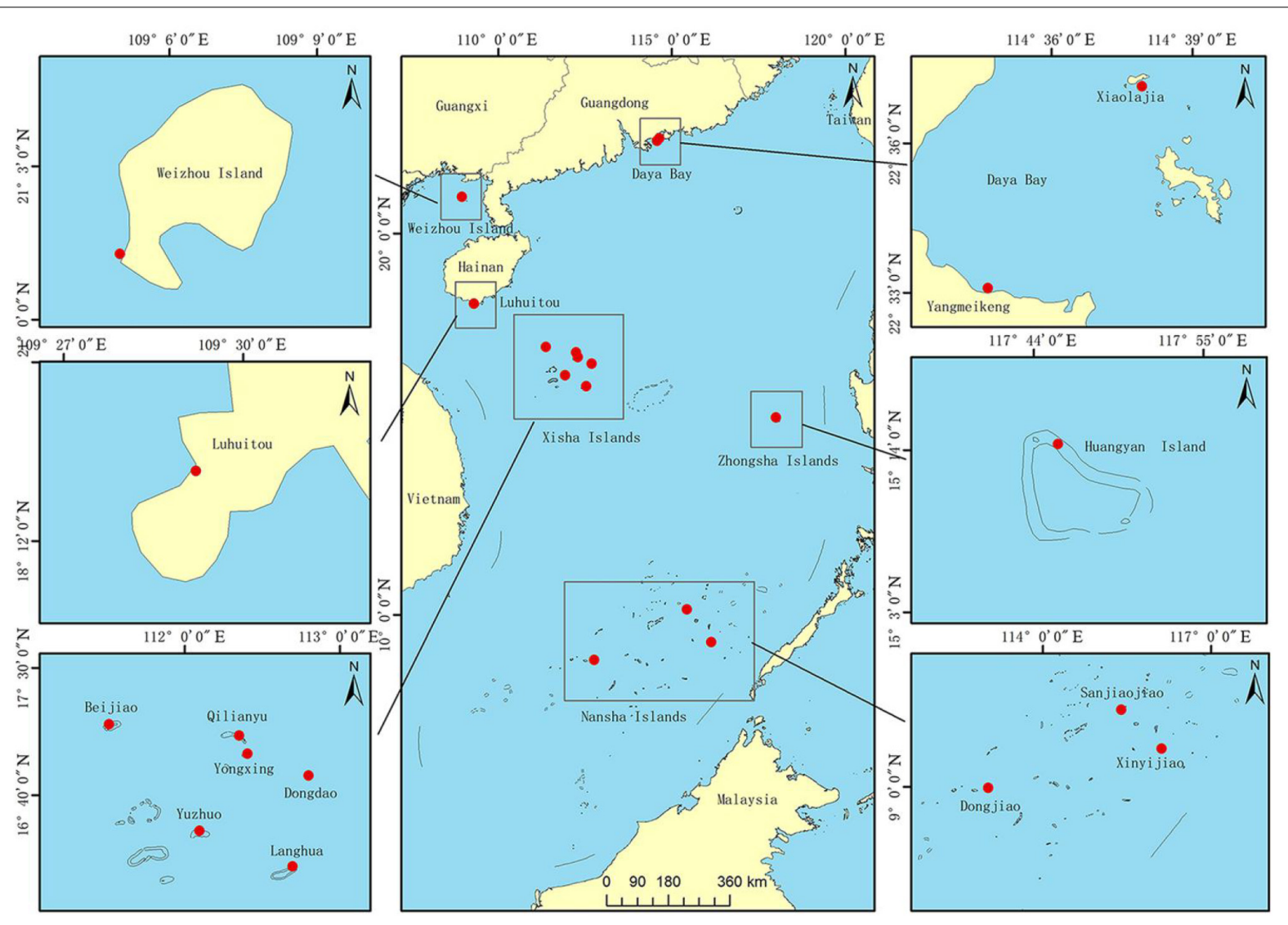

FIGURE 1 | Samples collected from sites in the South China Sea (SCS). Daya Bay is at the northern edge of Porites /utea distribution in the SCS, a region that also includes Xiaolajia and Yangmeikeng. Most coral colonies at Daya Bay have not developed into extensive coral reefs (Chen et al., 2007). Weizhou Island is in the Beibu Gulf at (northwestern SCS); colonies there have developed into extensive coral reefs. Sanya Bay is in the tropical region of the sea. Xisha Islands, Zhongsha Islands, and Nansha Islands are also part of the tropical region. Xisha Islands include Beijiao, Qilianyu, Yongxing, Dongdao, Yuzhuo, and Langhua. Nansha includes Sanjiaojiao, Xinyijiao, and Dongjiao. 
was verified to ensure effective amplification of the DNA samples at each site.

\section{Data Analysis}

Unique multilocus genotypes (MLGs) were identified in GenAlex 6.502 (Peakall and Smouse, 2005), by requiring complete matches in all loci. The number of MLGs per population provides an estimate of $P$. lutea propagation patterns. GenAlex 6.502 was also used to analyze genetic diversity indices, including the average number of alleles per locus in the populations $(\mathrm{Na})$ and average number of effective alleles per locus in the populations $(\mathrm{Ne})$. The genetic variation was tested by Mantel test in GenAlex 6.502 (Peakall and Smouse, 2005). Observed heterozygosity ( $\mathrm{Ho}$ ) and expected heterozygosity $(\mathrm{He})$ were analyzed in MSA v4.0 (Dieringer and Schlötterer, 2003). FSTAT (Goudet, 1995) was used to calculate gene diversity $(G d)$ and pairwise $F_{\mathrm{ST}}\left(F_{\mathrm{ST}}<0.05\right.$, low genetic differentiation; $0.05<F_{\mathrm{ST}}<0.25$, moderate genetic differentiation; $F_{\mathrm{ST}}>0.25$, high genetic differentiation). Analysis of molecular variance and principal coordinates analysis (PCoA) were conducted for the geographic populations using GenAlex 6.502 (Peakall and Smouse, 2005; Chen et al., 2020). Based on a matrix of covariance computed from allele frequencies, PCoA can visualize genetic relationships across different latitudes (Peakall and Smouse, 2005). Correlations between genetic structure and geographical distance as well as environmental factors (average SST and SST variance) were determined using Mantel tests, which were performed in IBD (Bohonak, 2002) with 1,000 randomizations. The geographic distances between $P$. lutea populations were determined using Google Earth version 4.3 and followed the shortest route from the waterway.

The genetic structure was analyzed in STRUCTURE 2.3.4, a program that can estimate the most likely number of genetic clusters $(K)$ (Pritchard et al., 2000). The method on Delta $\mathrm{K}$ implement of program STRUCTURE is the widely and popular way to infer population genetic structure (Pritchard et al., 2000; Polato et al., 2010; Baums et al., 2012; Tay et al., 2015; Chen et al., 2020). STRUCTURE implements Bayesian cluster algorithms to assign genotypes to clusters that maximize deviation from Hardy-Weinberg equilibrium expectations and minimize linkage disequilibrium, providing an accurate representation of contemporary divergence (Hubisz et al., 2009). CONVERT (Glaubitz, 2004) was used to format the input data before using STRUCTURE. Correlated allele frequencies and admixed populations were also assumed. Values of $K=1-14$ were analyzed by running replicate simulations ( $\geq 3$ ) with $10^{6}$ Markov Chain Monte Carlo repetitions each, with a burn-in of $10^{5}$ iterations (Evanno et al., 2005; Polato et al., 2010). Each K value was run 10 times in STRUCTURE. The $K$ value based on the STRUCTURE output was determined using STRUCTURE HARVESTER (Earl and Vonholdt, 2012) to plot the log probability $[L(K)]$ of data over multiple runs and to compare the outcome with delta $K$ (Evanno et al., 2005). The results of the STRUCTURE run with the optimal $K$ were merged with CLUMPP (Jakobsson and Rosenberg, 2007) and then visualized using DISTRUCT version 1.1
(Rosenberg, 2004). For all analyses, significance was set at $P<0.05$.

\section{RESULTS}

\section{Multilocus Genotyping}

We verified that the selected microsatellite markers were suitable for our study. The locus failure rate was $0.33 \sim 5.96 \%$, with the lowest in PL0340 and the highest in PL1556, respectively (Supplementary Table 1). The overall missing loci in samples were $2.94 \%$.

Porites lutea in the SCS showed high genotypic diversity. Genetic analysis of $14 P$. lutea communities revealed 301 unique MLGs (Table 1). The Dongjiao coral reef site (Nansha Islands) possessed only one set of two identical MLGs (Table 1). This repeated $M L G$ is attributable to a single common genotype occurring across distinct patches within each population. Nevertheless, the high proportion of unique MLGs (mean $N g / N=0.99 \pm 0.13$, Table 1) confirmed the substantial diversity of $P$. lutea genotypes, possibly because of sexual reproduction, and indicated considerable clonal richness.

\section{Genetic Diversity of Porites lutea}

In our study populations, $\mathrm{Na}$ ranged from 6.000 to 9.750 and $\mathrm{Ne}$ ranged from 3.899 to 6.415 . Additionally, Ho ranged from 0.515 to 0.749 , He ranged from 0.685 to 0.844 , and Gd ranged from 0.632 to 0.839 (Table 2), According to the results (Supplementary Table 2), Fis ranged from -0.313 to 0.698. A small part of loci revealed significant deviation from HWE and was mainly found in Dongjiao population in Nansha Islands. These results for the alleles, effective number of alleles, gene diversity, and heterozygosity demonstrated that tropical $P$. lutea communities had high genetic diversity. Notably, subtropical $P$. lutea communities (particularly in Daya Bay) showed lower genetic diversity than in the tropical coral populations. In fact, tropical $P$. lutea were abundant, healthy, and formed reefs, whereas P. lutea in Daya Bay were scattered and did not form reefs.

\section{Genetic Structure of Porites lutea}

Coral populations from Daya Bay exhibited significant genetic variation compared to other tropical coral populations $\left(\Phi_{\mathrm{PT}}=0.129-0.290, P<0.01\right)$ (Table 3$)$. In particular, the Xiaolajia population exhibited strong genetic variation between the Yuzhuo, Langhua and Dongjiao populations. The Weizhou Island population showed moderate genetic variation compared with tropical populations $\left(\Phi_{\mathrm{PT}}=0.085-\right.$ 0.148, $P<0.01$ ) (Table 3). Notably, the Luhuitou population exhibited slight variation from other tropical populations (in addition to Beijiao, Dongdao, and Xinyijiao). Therefore, the genetic structure of $P$. lutea is likely related to the latitudinal gradient.

Pairwise $F_{\mathrm{ST}}$ values derived from microsatellite markers showed that the Xiaolajia and Yangmeikeng subtropical populations of Daya Bay were significantly genetically 
TABLE 2 | Genetic diversity of Porites lutea samples from the South China Sea estimated using eight microsatellite loci.

\begin{tabular}{lccccc}
\hline Site & Na & Ne & Gd & Ho & He \\
\hline Xiaolajia & 6.000 & 3.899 & 0.632 & 0.679 & 0.685 \\
Yangmeikeng & 6.125 & 4.304 & 0.735 & 0.515 & 0.758 \\
Weizhou Island & 6.875 & 4.670 & 0.792 & 0.728 & 0.795 \\
Luhuitou & 9.000 & 5.998 & 0.839 & 0.615 & 0.844 \\
Beijiao & 7.625 & 5.303 & 0.823 & 0.672 & 0.834 \\
Qilianyu & 9.750 & 6.415 & 0.819 & 0.624 & 0.835 \\
Yongxing & 8.625 & 6.095 & 0.807 & 0.648 & 0.825 \\
Dongdao & 8.750 & 6.153 & 0.815 & 0.669 & 0.828 \\
Yuzhuo & 8.500 & 5.497 & 0.787 & 0.747 & 0.803 \\
Langhua & 7.250 & 4.928 & 0.784 & 0.732 & 0.798 \\
Huangyan & 8.125 & 5.996 & 0.783 & 0.569 & 0.802 \\
Sanjiaojiao & 9.250 & 5.987 & 0.813 & 0.602 & 0.824 \\
Xinyijiao & 8.875 & 6.254 & 0.827 & 0.602 & 0.837 \\
Dongjiao & 7.875 & 5.509 & 0.771 & 0.749 & 0.797 \\
\hline Data were analyzed & based on & the individual site and & locus. Na, average \\
number of alleles observed; Ne, average number of effective alleles per locus in \\
populations; Gd, gene diversity; Ho, average observed heterozygosity; He, average \\
expected heterozygosity.
\end{tabular}

differentiated from tropical coral populations $\left(F_{\mathrm{ST}}=0.1170\right.$ $0.2361, P<0.05)$. These Daya Bay populations differed significantly from tropical populations (Supplementary Table 3). The results of PCoA indicated that the P. lutea populations formed two genetic clusters: subtropical populations and tropical populations (Figure 2). Notably, population of Weizhou Island was slightly isolated from the Daya Bay populations (Figure 2).

\section{Cluster Analysis of Porites lutea}

According to plots of Delta K (Supplementary Figure 1) and LnP (D) (Supplementary Figure 2) from STRUCTURE analysis, the 14 P. lutea populations could be grouped into two genetic clusters with the optimal $K=2$ (Figure 3). The subtropical populations of Daya Bay and Weizhou Island, and tropical populations formed two distinct and closely knit genetic units (Figure 3). The green cluster was found at high frequencies in samples collected from Daya Bay and Weizhou but with lower frequencies in samples from other coral reef sites. But green and little red clusters were found on Weizhou Island. The green clusters with a lower frequency were found on tropical populations. The red clusters were mainly found on tropical populations.

\section{Correlations Between Environment Factors and Genetic Structure of Porites lutea}

We acquired SST data covering January 1982 to December 2018 from the KNMI Climate Explorer ${ }^{1}$ (Figures 4A,B). Initial analysis indicated that the subtropical and tropical regions widely varied in seasonal SST. The monthly average SST was low in the subtropical coral reefs of Daya Bay and Weizhou Island. In the tropical regions, including the Xisha Islands, Zhongsha Islands, and Nansha Islands, the SST was relatively stable and high (Figures 4A,B).

The results of the Mantel tests showed that genetic variation $\left(\Phi_{\mathrm{PT}}\right)$ was positively correlated with the average SST $\left(R^{2}=0.3995, P=0.001\right)$, SST variation $\left(R^{2}=0.3860, P=0.001\right)$, and geographic distance $\left(R^{2}=0.2358, P=0.003\right.$, Figure 5). Geographic distance had a relatively small impact on genetic variation. In addition, $F_{S T}$ was positively correlated with the average SST $\left(R^{2}=0.3764, P=0.001\right)$, SST variation $\left(R^{2}=0.3525\right.$, $P=0.001)$, and geographic distance $\left(R^{2}=0.2105, P=0.003\right.$, Supplementary Figure 3). This result was consistent with that of $\Phi_{\text {PT }}$. Therefore, SST and geographic distance were the

${ }^{1}$ http://climexp.knmi.nl/start.cgi

TABLE 3 | Pairwise $\Phi_{\text {PT }}$ values of Porites /utea in the South China Sea.

\begin{tabular}{|c|c|c|c|c|c|c|c|c|c|c|c|c|c|c|}
\hline$\Phi_{\mathrm{PT}}$ & XLJ & YMK & WZ & LHT & BJ & QLY & $Y X$ & DD & $Y Z$ & LH & HY & SJJ & XYJ & DJ \\
\hline YMK & 0.047 & & & & & & & & & & & & & \\
\hline LHT & 0.211 & 0.129 & 0.085 & & & & & & & & & & & \\
\hline BJ & 0.232 & 0.157 & 0.119 & 0.039 & & & & & & & & & & \\
\hline QLY & 0.217 & 0.139 & 0.107 & 0.051 & 0.022 & & & & & & & & & \\
\hline $\mathrm{DD}$ & 0.238 & 0.161 & 0.090 & 0.040 & 0.022 & 0.006 & 0.014 & & & & & & & \\
\hline$Y Z$ & 0.289 & 0.223 & 0.148 & 0.098 & 0.054 & 0.020 & 0.042 & 0.028 & & & & & & \\
\hline LH & 0.271 & 0.196 & 0.103 & 0.066 & 0.064 & 0.056 & 0.051 & 0.057 & 0.096 & & & & & \\
\hline $\mathrm{HY}$ & 0.232 & 0.147 & 0.130 & 0.054 & 0.031 & 0.009 & 0.025 & 0.033 & 0.033 & 0.076 & & & & \\
\hline SJJ & 0.226 & 0.147 & 0.115 & 0.058 & 0.025 & 0.007 & 0.006 & 0.027 & 0.043 & 0.065 & 0.006 & & & \\
\hline$X Y J$ & 0.218 & 0.149 & 0.117 & 0.047 & 0.054 & 0.012 & 0.013 & 0.035 & 0.047 & 0.062 & 0.030 & 0.005 & & \\
\hline
\end{tabular}

Significant $\Phi_{\mathrm{PT}}$ values (sequential-Bonferroni-corrected $P$ < 0.05) marked in bold. Xiaolajia (XLJ), Yangmeikeng (YMK), Weizhou Island (WZ), Luhuitou (LHT), Beijiao (BJ), Qilianyu (QLY), Yongxing (YX), Dongdao (DD), Yuzhuo (YZ), Langhua (LH), Huangyan (HY), Sanjiaojiao (SJJ), Xinyijiao (XYJ), Dongjiao (DJ).

The bold values mean significant $\phi_{\mathrm{PT}}$. 


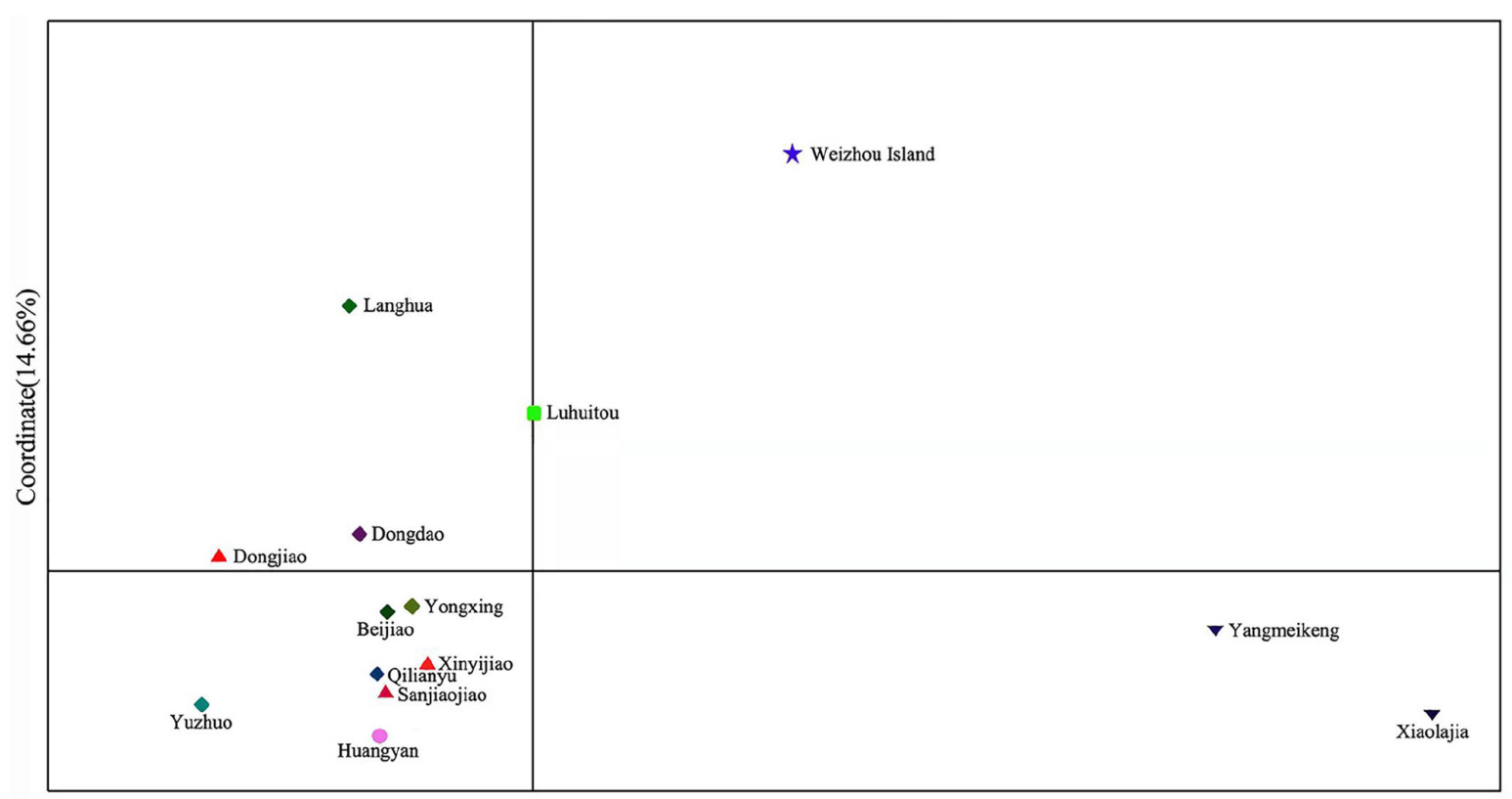

Coordinate(55.24\%)

FIGURE 2 | Principal coordinate analysis (PCOA) of samples from the South China Sea.

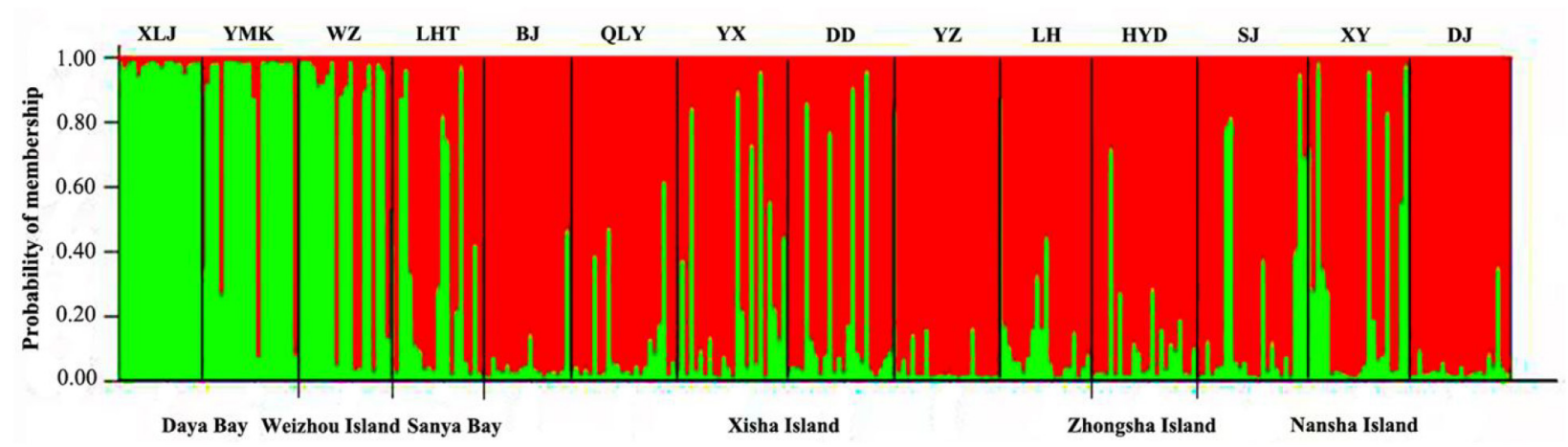

FIGURE 3 | Cluster analysis of Porites lutea in the South China Sea performed using STRUCTURE (optimal $K=2$ ). The $y$-axis indicates the membership probability of each site $(n=14)$ in distinct population clusters (different colors). Sampling sites are identified along the $x$-axis.

dominant factors determining the genetic structure of $P$. lutea in the SCS. The SST had a stronger influence compared with geographic distance.

\section{DISCUSSION}

\section{Tropical Porites lutea Populations May Have High Adaptive Potential}

Using microsatellite markers, we identified 301 unique MLGs in $14 P$. lutea populations. This result suggests that $P$. lutea reproduces largely via sexual propagation on scales of $5 \mathrm{~m}$ and greater and has abundant gene diversity. The genetic diversity of tropical $P$. lutea populations was relatively high but decreased from south to north with the lowest in Daya Bay. Numerous species originate close to the equator, a region with a stable SST and sunny environment (Roy et al., 1998; Jansson et al., 2013). Fossil and phylogenetic evidence support the latitudinal diversity gradient (Roy et al., 1998; Jansson et al., 2013). Additionally, the monthly average SST decreased significantly with increasing latitude (Figure 4). Thus, SST differences across latitude might strongly influence the genetic diversity gradient of P. lutea in the SCS.

The adaptability of organisms is mainly influenced by reproduction patterns and genetic diversity (Bernhardt and Leslie, 2013; Wu et al., 2021). Our findings suggest that sexual reproduction and rich genetic diversity will benefit the adaptability of $P$. lutea in tropical areas. First, corals add new alleles to the gene pool through sexual recombination, increasing within-population genotypic diversity 

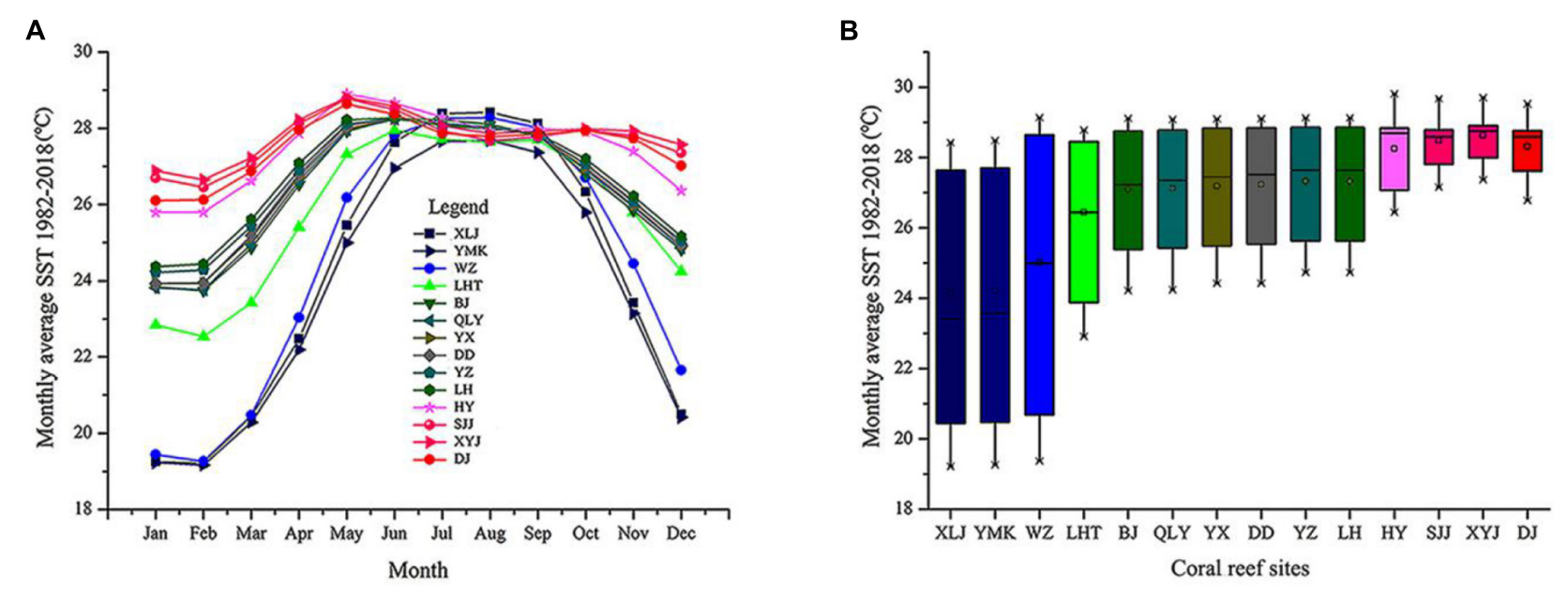

FIGURE 4 | Monthly average sea surface temperatures (SST) from 1982 to 2018 for 14 coral reef sites in the South China Sea. (A) Monthly averages and standard deviations of SST at all coral sites. (B) Box plots indicating annual mean, minimum, and maximum seasonal SST, grouped by coral reef sites.

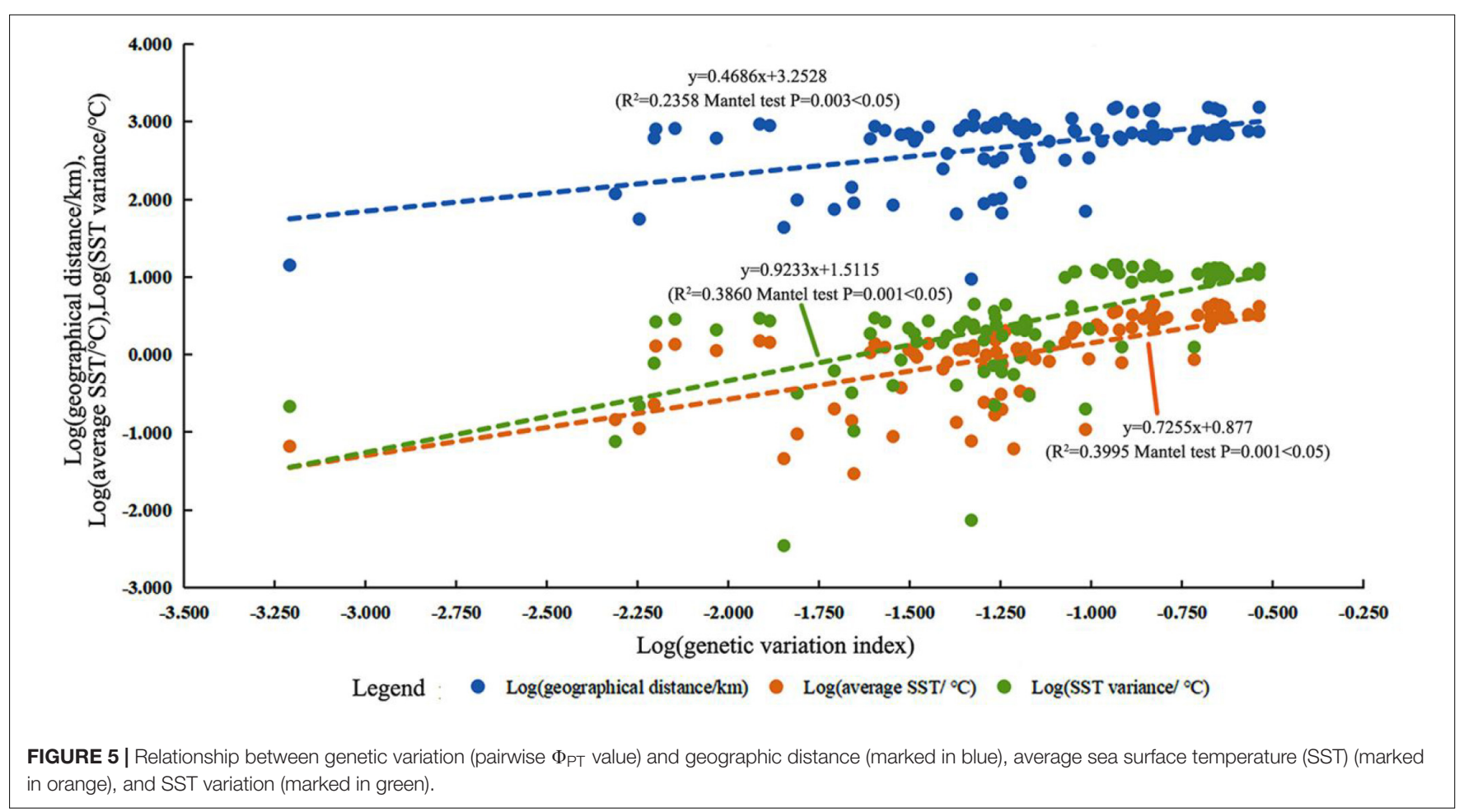

(Lasker and Coffroth, 1999; Hellberg and Taylor, 2002). Sexual reproduction allows coral larvae to inherit heat tolerance from both parents (Dixon et al., 2015; Kleypas et al., 2016). High genetic diversity enhances population sustainability over evolutionary time scales by providing sufficient alleles for adapting to future environmental change (Ayre and Hughes, 2004; Williams et al., 2014) through natural selection (Ficetola and Auré, 2011). Second, abundant genotypic diversity in populations is beneficial for improving fitness, stress response, and ecosystem function on an ecological time scale (Johnso et al., 2006; Hughes et al., 2008; Hughes and Stachowicz, 2009).
Third, larval dispersal also increases genotypic diversity, a key factor affecting the population size and genetic diversity (Tay et al., 2015).

In Western Australia, Pocillopora damicornis populations in high-latitude areas exhibited reduced genetic diversity and restricted gene flow and were more vulnerable to global climate change due to their limited adaptability (Thomas et al., 2017). Turbinaria peltata populations had lower genetic diversity in the northern SCS, revealing their poor evolutionary potential (Wu et al., 2021). Compared to the subtropical $P$. lutea populations and the two corals above, tropical P. lutea 
populations may have high adaptive potential. Furthermore, compared to Acropora corals in Luhuitou, $P$. lutea in the SCS had high zooxanthellae density. The primary dominant symbiont in $P$. lutea (C15) exhibits high thermal tolerance (LaJeunesse et al., 2010; Chen et al., 2019). Therefore, P. lutea was less susceptible to bleaching and had a high tolerance to thermal stress event (Xu et al., 2017; Qin et al., 2019). Indeed, massive corals, including $P$. lutea, have experienced the slowest decline in the face of rapidly degrading global coral reefs (Huang et al., 2021). Taken together, our results suggest that tropical $P$. lutea populations may be highly adaptable.

\section{Spatial Sea Surface Temperature Variation Across Latitudes Affected Porites lutea Genetic Structure in the South China Sea}

We detected significant genetic divergence between subtropical (particularly in Daya Bay) and tropical P. lutea populations, as confirmed by the pairwise $F_{S T}$ values (Supplementary Table 3). Compared with the results obtained by Huang et al. (2018), we observed a stronger latitude-based difference in the genetic structure and identified a latitudinal structure gradient. Microsatellites are widely dispersed in eukaryotic genomes and have higher levels of polymorphism than nuclear markers (Baums et al., 2005; Wang et al., 2009). Thus, the genetic structure can be identified to a finer resolution using microsatellites (Ridgway and Gates, 2006). In this study, the SST dominated the genetic structure of $P$. lutea in the SCS. Meanwhile, geographic distance had a relatively small impact on genetic structure. Similarly, the SST had a closer connection with genetic structure than geographical isolation of Turbinaria peltata in the north SCS (Wu et al., 2021).

Temperature is a crucial environmental factor determining the distribution of poikilothermic invertebrates over latitudinal clines, particularly in corals (Parmesan, 2006; Li et al., 2009; Obura, 2012; Howells et al., 2014). The connectivity and structure of coral populations are directly tied to temperature across different latitudes (Hoegh-Guldberg and Pearse, 1995; Levin, 2006; Bradbury et al., 2008). Temperature is the dominant influence on the rates of fundamental biochemical processes regulating development and survival (O'Connor et al., 2007). Ecological simulation experiments indicated that bleaching would occur if $P$. lutea was exposed to $14^{\circ} \mathrm{C}$ for 3 days ( $\mathrm{Li}$ et al., 2009). Furthermore, temperature can alter metabolic rates in individuals, thereby influencing the rates of genetic variation and evolution among populations (Rohde, 1992; Rosenzweig, 1995; Allen et al., 2002; O’Connor et al., 2007). Finally, the SST impacts the spawning period of coral and probably influences gene exchange by driving asynchronous spawning across latitudes (Hanafy et al., 2010; Howells et al., 2014). The coral spawning period in the Gulf of Oman (northwest Indian Ocean) is directly associated with latitudinal variation and is likely influenced by the SST and timing of lunar cycles (Howells et al., 2014). The spawning period at low latitudes is generally earlier than that at higher latitudes, which may be influenced by the SST (Wei et al., 2020). In addition, studies demonstrated that the same coral genus had different gamete development cycles and spawning period in different areas (Baird et al., 2009; Yang, 2013). Hence, the spawning period of $P$. lutea at different latitudes might be different. The lack of synchronization in spawning periods possible reduces larval recruitment between coral reef sites, ultimately affecting gene exchange and genotype combination between corals at different latitudes.

Geographic distance was also significantly positively correlated with genetic differentiation. The broadcast spawning strategy and high environmental tolerance help species to disperse over long distances (Polato et al., 2010; Baums et al., 2012). The $P$. lutea populations in this study were across $13^{\circ}$ of latitude, with the largest distance between them being $1,500 \mathrm{~km}$. However, there are no consistent ocean currents in the SCS to transport corals over long distances in a certain direction (Huang et al., 1992; Van der Ven et al., 2016). Therefore, geographic distance had a relatively small impact on genetic structure. Geographic distance was reported to affect the genetic structure of T. peltata in the northern SCS (Wu et al., 2021). Taken together, our results clearly indicate that latitudinal differences in the SST and geographic distance were the main factors influencing the genetic structure of $P$. lutea in the SCS.

\section{Management Implications Under Climate Change}

As discussed, tropical P. lutea populations may have a greater adaptability to anthropogenic disturbance and environmental change because of their high genetic diversity and sexual reproduction. In recent years, although tropical $P$. lutea populations may be more adaptable, coral bleaching has occurred frequently, and coral reef coverage has declined due to external environmental changes. We found that tropical $P$. lutea grew well in the SCS and had high coverage. However, high-latitude areas are regarded as a refuge for tropical coral species (Riegl, 2003; Beger et al., 2014; Thomas et al., 2017). As the global temperature rises, the SST of subtropical areas has become increasingly suitable for coral growth, and thus corals may shift their distributional ranges toward higher latitudes (Halfar et al., 2005; Chen et al., 2009). For instance, two tropical coral species have been expanding toward higher latitudes with a diffusion of $14 \mathrm{~km} / \mathrm{a}$ since the 1930s during a century of global warming (Yamano et al., 2011). However, other factors may prevent the consolidation of subtropical regions as new coral refuges. Severe anthropogenic activities deteriorated the marine ecological environment in the subtropics. In particular, subtropical coral reefs of the SCS are mainly distributed along the coast, making them more susceptible to anthropogenic impact. In general, coral reefs are among the most vulnerable and easily disturbed ecosystems and need to be protected systematically. Firstly, the anthropogenic impact in relatively high latitudes should be removed to protect potential further refuges. Secondly, measures to enhance genetic potential and adaptability should be taken in the SCS. Thirdly, stress-tolerant species or populations are needed for artificial transplantation to help natural populations cope with global change. 


\section{CONCLUSION}

Tropical $P$. lutea populations in the SCS show greater evolutionary potential because they exhibit abundant genetic diversity and sexual reproduction. The genetic diversity of $P$. lutea generally changes with increasing latitude, a gradient that appears largely due to latitudinal SST variation. Subtropical coral populations have lower genetic diversity, and thus, relatively poor genetic resilience in response to low average SST and human activities. Analyses of genetic variation, $F_{\mathrm{ST}}$, and genetic clusters revealed that subtropical $P$. lutea populations are genetically distinct from the tropical populations. SST is likely to be a key factor affecting these genetic differences. Thus, protection measures could be considered to enhance coral cover at reef sites that would likely act as refuges of subtropical areas in the future, such as removing anthropogenic impacts (port construction, overfishing, and city development) and promoting artificial transplantation. Our research provides insight into coral genetics and scientific guidance and a theoretical basis for the protection and restoration of coral reefs.

\section{DATA AVAILABILITY STATEMENT}

The original contributions presented in the study are included in the article/Supplementary Material, further inquiries can be directed to the corresponding author.

\section{REFERENCES}

Allen, A. P., Brown, J. H., and Gillooly, J. F. (2002). Global biodiversity, biochemical kinetics, and the energetic-equivalence rule. Science 297, 1545-1548. doi: 10. $1126 /$ science. 1072380

Ayre, D. J., and Hughes, T. P. (2004). Climate change, genotypic diversity and gene flow in reef-building corals. Ecol. Lett. 7, 273-278. doi: 10.1111/j.1461-0248. 2004.00585.x

Baird, A. H., Birrel, C. L., Hughes, T. P., Mcdonald, A., Nojima, S., Page, C. A. et al. (2009). Latitudinal variation in reproductive synchrony in Acropora assemblages: Japan vs. Australia Galaxea. J. Coral Reef Studies 11, 101-108. doi: 10.3755/galaxea.11.101

Barrett, R. D. H., and Schluter, D. (2008). Adaptation from standing genetic variation. Trends Ecol. Evol. 23, 38-44. doi: 10.1016/j.tree.2007.09.008

Baums, I. B., Boulay, J. N., Polato, N. R., and Hellberg, M. E. (2012). No gene flow across the Eastern Pacific Barrier in the reef-building coral Porites lobata. Mol. Ecol. 21, 5418-5433. doi: 10.1111/j.1365-294X.2012.05733.x

Baums, I. B., Hughes, C. R., and Hellberg, M. E. (2005). Mendelian microsatellite loci for the Caribbean coral Acropora palmata. Mar. Ecol. Prog. Ser. 288, 115-127. doi: 10.3354/meps288115

Beger, M., Sommer, B., Harrison, P. L., Smith, S. D., and Pandolfi, J. M. (2014). Conserving potential coral reef refuges at high latitudes. Divers. Distrib. 20, 245-257. doi: 10.1111/ddi.12140

Bernhardt, J. R., and Leslie, H. M. (2013). Resilience to climate change in coastal marine ecosystems. Annu. Rev. Mar. Sci. 5, 371-392. doi: 10.1146/annurevmarine-121211-172411

Bohonak, A. J. (2002). IBD (isolation by distance): a program for analyses of isolation by distance. J. Hered. 93, 153-154. doi: 10.1093/jhered/93.2.153

Bradbury, I. R., Laurel, B. J., Robichaud, D., Rose, G. A., Snelgrove, P. V. R., Gregory, R. S., et al. (2008). Discrete spatial dynamics in a marine broadcast spawner: re-evaluating scales of connectivity and habitat associations in

\section{AUTHOR CONTRIBUTIONS}

$\mathrm{KY}$ and $\mathrm{WH}$ designed the research. $\mathrm{BC}, \mathrm{XH}$, and $\mathrm{ZQ}$ contributed study materials. YL and ML performed the experiments. YL analyzed the data and generated all images. YL and WH wrote the manuscript. All authors reviewed the manuscript.

\section{FUNDING}

This work was financially supported by the National Natural Science Foundation of China (Grant Nos. 42090041, 41866006, and 42030502) and Guangxi Scientific Projects (Nos. AD17129063 and AA17204074).

\section{ACKNOWLEDGMENTS}

We would like to thank Editage (www.editage.cn) for English language editing. We would also like to thank Luo Weicheng for helping draw the geographic distribution map.

\section{SUPPLEMENTARY MATERIAL}

The Supplementary Material for this article can be found online at: https://www.frontiersin.org/articles/10.3389/fmars. 2022.791149/full\#supplementary-material

Atlantic cod (Gadus morhua L.) in coastal Newfoundland. Fish. Res. 91, 299309. doi: 10.1016/j.fishres.2007.12.006

Chen, B., Yu, K. F., Liang, J. Y., Huang, W., Wang, G. H., Su, H. F., et al. (2019). Latitudinal variation in the molecular diversity and community composition of Symbiodiniaceae in coral from the South China Sea. Front. Microbiol. (Section Aquatic Microbiology) 10:1278. doi: 10.3389/fmicb.2019.01278

Chen, B., Yu, K. F., Qin, Z. J., Liang, J. Y., Wang, G. H., Huang, X. Y., et al. (2020). Dispersal, genetic variation, and symbiont interaction network of heat-tolerant endosymbiont Durusdinium trenchii: insights into the adaptive potential of coral to climate change. Sci. Total Environ. 723:138026. doi: 10.1016/j.scitotenv. 2020.138026

Chen, J. E., Cui, G., Xin, W., Jin, L. Y., and Manuel, A. (2018). Recent expansion of heat-activated retrotransposons in the coral symbiont. ISME J. 12, 639-643. doi: 10.1038/ismej.2017.179

Chen, T. R., Yu, K. F., Shi, Q., Li, S., and Gilbert, J. (2009). Twenty-five years of change in scleractinian coral communities of Daya Bay (northern South China Sea) and its response to the $2008 \mathrm{AD}$ extreme cold climate event. Chin. Sci. Bull. 54, 2107-2117. doi: 10.1007/s11434-009-0007-8

Chen, T. R., Yu, K. F., Shi, Q., Li, S., and Wang, S. (2007). Distribution and status of Scleractinian coral communities in the Daya Bay, Guangdong. Trop. Geogr. 27, 491-498.

Dieringer, D., and Schlötterer, C. (2003). Microsatellite analyser (MSA): a platform independent analysis tool for large microsatellite data sets. Mol. Ecol. Notes 3, $167-169$.

Dixon, G. B., Davies, S. W., Aglyamova, G. A., and Meyer, E. (2015). Genomic determinants of coral heat tolerance across latitudes. Coral Reefs 348, 14601462. doi: 10.1126/science.1261224

Earl, D. A., and Vonholdt, B. M. (2012). Structure Harvester: a website and program for visualizing structure output and implementing the Evanno method. Cons Genet Res 4: 359-361. Conserv. Genet. Resour. 4, 359-361. doi: 10.1007/s12686-011-9548-7 
Evanno, G. S., Regnaunt, S. J., and Goudet, J. (2005). Detecting the number of clusters of individuals using the software structure: a simulation study. Mol. Ecol. 14, 2611-2620. doi: 10.1111/j.1365-294X.2005.02553.x

Ficetola, G. F., and Auré, L. B. (2011). Conserving adaptive genetic diversity in dynamic landscapes. Mol. Ecol. 20, 1569-1571. doi: 10.1111/j.1365-294x.2011. 05024.x

Glaubitz, J. C. (2004). Convert: a user-friendly program to reformat diploid genotypic data for commonly used population genetic software packages. $\mathrm{Mol}$. Ecol. Notes 4, 309-310. doi: 10.1111/j.1471-8286.2004.00597.x

Goudet, J. (1995). FSTAT (version 1.2): a computer program to calculate F-statistics. J. Hered. 86, 484-486. doi: 10.1093/oxfordjournals.jhered.a111627

Halfar, J., Godinez-Orta, L., Riegl, B., and Valdez-Holguin, J. E. (2005). Living on the edge: high-latitude Porites carbonate production under temperate eutrophic conditions. Coral Reefs 24, 582-592. doi: 10.1007/s00338-005-0029-x

Hanafy, M. H., Aamer, M. A., Habib, M., Rouphael, A. B., and Baird, A. (2010). Synchronous reproduction of corals in the Red Sea. Coral Reefs 29, 119-124. doi: 10.1007/s00338-009-0552-2

Hellberg, M. E., and Taylor, M. S. (2002). Genetic analysis of sexual reproduction in the dendrophylliid coral Balanophyllia elegans. Mar. Biol. 141, 629-637. doi: 10.1007/s00227-002-0861-2

Hoegh-Guldberg, O., and Bruno, J. F. (2010). The impact of climate change on the World's marine ecosystems. Science 328, 1523-1528. doi: 10.1126/science. 1189930

Hoegh-Guldberg, O., and Pearse, J. S. (1995). Temperature, food Availability, and the development of marine invertebrate larvae. Am. Zool. 35, 415-425.

Howells, E. J., Abrego, D., Vaughan, G. O., and Burt, J. A. (2014). Coral spawning in the Gulf of Oman and relationship to latitudinal variation in spawning season in the northwest Indian Ocean. Sci. Rep. 4:7484. doi: 10.1038/srep07484

Huang, H., Chen, Z., and Huang, L. T. (2021). Status of Coral Reefs in China During 2010-2019. Beijing: Oceanpress.

Huang, Q. Z., Wang, W. Z., Li, Y. X., Li, Z. W., and Mao, M. (1992). General situations of the current and eddy in the South China Sea. Adv. Earth Science 7, 1-9.

Huang, W., Li, M., Yu, K. F., Wang, Y. H., Li, J. J., and Liang, J. Y. (2018). Genetic diversity and large-scale connectivity of the scleractinian coral Porites lutea in the South China Sea. Coral reefs 37, 1259-1271. doi: 10.1007/s00338-0181724-8

Hubisz, M., Falush, D., Stephens, M., and Pritchard, J. (2009). Inferring weak population structure with the assistance of sample group information. Mol. Ecol. Resour. 9, 1322-1332. doi: 10.1111/j.1755-0998.2009.02591.x

Hughes, A. R., Inouye, B. D., Johnson, M. T. J., and Underwood, N. (2008). Ecological consequences of genetic diversity. Ecol. Lett. 11, 609-623.

Hughes, A. R., and Stachowicz, J. J. (2004). Genetic diversity enhances the resistance of a seagrass ecosystem to disturbance. Proc. Natl. Acad. Sci. U.S.A. 101, 8998-9002. doi: 10.1073/pnas.0402642101

Hughes, A. R., and Stachowicz, J. J. (2009). Ecological impacts of genotypic diversity in the clonal seagrass Zostera marina. Ecology 90, 1412-1419. doi: 10.1890/07-2030.1

Hughes, T. P., Kerry, J. T., Álvarez-Noriega, M., Andeson, K. D., Baird, A. H., Babcock, R. C., et al. (2017). Global warming and recurrent mass bleaching of corals. Nature 543, 373-377. doi: 10.1038/nature21707

Jakobsson, M., and Rosenberg, N. A. (2007). CLUMPP: a cluster matching and permutation program for dealing with label switching and multimodality in analysis of population structure. Bioinformatics 23:1801. doi: 10.1093/ bioinformatics/btm 233

Jansson, R., Rodríguez-Castañeda, G., and Harding, L. E. (2013). What can multiple phylogenies say about the latitudinal diversity gradient? A new look at the tropical conservatism, out of the tropics, and diversification rate hypotheses. Evolution 67, 1741-1755. doi: 10.1111/evo.12089

Johnso, M. T. J., Lajeunesse, M. J., and Agrawal, A. A. (2006). Additive and interactive effects of plant genotypic diversity on arthropod communities and plant fitness. Ecol. Lett. 9, 24-34. doi: 10.1111/j.1461-0248.2005. 00833.x

Keshavmurthy, S., Hsu, C. M., Kuo, C. Y., Meng, P. J., Wang, J. T., and Chen, C. A. (2012). Symbiont communities and host genetic structure of the brain coral Platygyra verweyi, at the outlet of a nuclear power plant and adjacent areas. Mol. Ecol. 21, 4393-4407. doi: 10.1111/j.1365-294X.2012.05704.x
Kleypas, J. A., Thompson, D. M., Castruccio, F. S., Curchister, E. N., Pinsky, M., and Watson, J. R. (2016). Larval connectivity across temperature gradients and its potential effect on heat tolerance in coral populations. Glob. Chang. Biol. 22, 3539-3549. doi: 10.1111/gcb.13347

Knittweis, L., Kraemer, W. E., Timm, J., and Kochzius, M. (2009). Genetic structure of Heliofungia actiniformis (Scleractinia: Fungiidae) populations in the Indo-Malay Archipelago: implications for live coral trade management efforts. Conserv. Genet. 10, 241-249. doi: 10.1007/s10592-008-9566-5

LaJeunesse, T. C., Pettay, D. T., Sampayo, E. M., Phongsuwan, N., Brown, B., Obura, D. O., et al. (2010). Long-standing environmental conditions, geographic isolation and host-symbiont specificity influence the relative ecological dominance and genetic diversification of coral endosymbionts in the genus Symbiodinium. J. Biogeogr. 37, 785-800. doi: 10.1111/j.1365-2699.2010. 02273.x

Lasker, H. R., and Coffroth, M. A. (1999). Responses of clonal reef taxa to environmental change. Am. Zool. 39, 92-103. doi: 10.1093/icb/39.1.92

Levin, L. A. (2006). Recent progress in understanding larval dispersal: new directions and digressions. Integr. Comp. Biol. 46, 282-297. doi: 10.1093/icb/ icj024

Li, S., Yu, K. F., Shi, Q., Chen, T. R., and Zhao, M. X. (2009). Low water temperature tolerance and responding mode of scleractinian corals in Sanya Bay. Chin. J. Appl. Ecol. 20, 2289-2295.

Liang, J. Y., Yu, K. F., Wang, Y. H., Huang, X. Y., Huang, W., Qin, Z. J., et al. (2017). Distinct bacterial communities associated with massive and branching scleractinian corals and potential linkages to coral susceptibility to thermal or cold Stress. Front. Microbiol. 8:979. doi: 10.3389/fmicb.2017.00979

Magalon, H., Adjeroud, M., and Veuille, M. (2005). Patterns of genetic variation do not correlate with geographical distance in the reef-building coral Pocillopora meandrina in the South Pacific. Mol. Ecol. 14, 1861-1868. doi: 10.1111/j.1365294x.2005.02430.x

Magalon, H., Samadi, S., Richard, M., Adjeroud, M., and Veuille, M. (2004). Development of coral and zooxanthella-specific microsatellites in three species of Pocillopora (Cnidaria. Scleractinia) from French Polynesia. Mol. Ecol. Resour. 4, 206-208. doi: 10.1111/j.1471-8286.2004.00618.x

Mclachlan, R. H., Price, J. T., Solomon, S. L., and Grottoli, A. G. (2020). Thirty years of coral heat-stress experiments: a review of methods. Coral Reefs 39, 885-902. doi: 10.1007/s00338-020-01931-9

Meyers, L. A., Fredric, D. A., and Lachmann, M. (2005). Evolution of genetic potential. PLoS Comput. Biol. 1:e32. doi: 10.1371/journal.pcbi.0010032

Miller, K. J., and Ayre, D. J. (2010). Protection of Genetic Diversity and Maintenance of Connectivity among Reef Corals within Marine Protected Areas. Biol. Conserv. 22, 1245-1254.

Ng, W. C., and Morton, B. (2003). Genetic structure of the scleractinian coral Platygyra sinensis in Hong Kong. Mar. Biol. 143, 963-968. doi: 10.1007/s00227003-1159-8

Obura, D. (2012). The diversity and biogeography of Western Indian Ocean Reef-Building Corals. PLoS One 7:e45013. doi: 10.1371/journal.pone.0045013

O’Connor, M., Bruno, J., Gaines, S. D., Halpern, B. S., Sarah, E., Kinlan, B. P., et al. (2007). Temperature control of larval dispersal and the implications for marine ecology, evolution, and conservation. Proc. Natl. Acad. Sci. U.S.A. 104, 1266-1271. doi: 10.1073/pnas.0603422104

Parmesan, C. (2006). Ecological and evolutionary responses to recent climate change. Annu. Rev. Ecol. Evol. Syst. 37, 637-669. doi: 10.1146/annurev.ecolsys. 37.091305.110100

Peakall, R., and Smouse, P. E. (2005). GENALEX 6: genetic analysis in Excel. Population genetic software for teaching and research. Mol. Ecol. Notes 6, 288-295. doi: 10.1093/bioinformatics/bts460

Polato, N. R., Concepcion, G. T., Toonen, R. J., and Baums, I. B. (2010). Isolation by distance across the Hawaiian Archipelago in the reef-building coral Porites lobata. Mol. Ecol. 19, 4661-4677. doi: 10.1111/j.1365-294X.2010.04836.x

Pritchard, J. K., Stephens, M., and Donnelly, P. (2000). Inference of population structure using multilocus genotype data. Genetics 155, 9197-9201.

Qin, Z. J., Yu, K. F., Wang, Y. H., Xu, L. J., Huang, X. Y., Chen, B., et al. (2019). Spatial and inter-generic variation in physiological indicators of corals in the South China Sea: insights into their current state and their adaptability to environmental stress. J. Geophys. Res. Oceans 124, 3317-3332. doi: 10.1029/ 2018JC014648 
Ridgway, T., and Gates, R. D. (2006). Why are there so few genetic markers available for coral population analyses? Symbiosis 41, 1-7.

Riegl, B. (2003). Climate change and coral reefs: different effects in two highlatitude areas (Arabian Gulf, South Africa). Coral Reefs 22, 433-446. doi: 10. 1007/s00338-003-0335-0

Rohde, K. (1992). Latitudinal gradients in species diversity: the search for the primary cause. Oikos 65, 514-527. doi: 10.2307/3545569

Rosenberg, N. A. (2004). Distruct: a program for the graphical display of population structure. Mol. Ecol. Notes 4, 137-138. doi: 10.1046/j.1471-8286. 2003.00566.x

Rosenzweig, M. L. (1995). Species Diversity in Space and Time. Cambridge: Cambridge University Press.

Roy, K., Jablonski, D., Valentine, J. W., and Rosenberg, G. (1998). Marine latitudinal diversity gradients: tests of causal hypotheses. Proc. Natl. Acad. Sci. U.S.A.95, 3699-3702. doi: 10.1073/pnas.95.7.3699

Severance, E. G., Szmant, A. M., and Karl, S. A. (2010). Microsatellite loci isolated from the Caribbean coral, Montastraea annularis. Mol. Ecol. Resour. 4, 74-76.

Tay, Y. C., Noreen, A. M. E., Suharsono, Chou, L. M., and Todd, P. A. (2015). Genetic connectivity of the broadcast spawning reef coral Platygyra sinensis, on impacted reefs, and the description of new microsatellite markers. Coral Reefs 34, 301-311.

Thomas, L., Kennington, W. J., Evans, R. D., Richard, D., Kendrick, G. A., and Stat, M. (2017). Restricted gene flow and local adaptation highlight the vulnerability of high-latitude reefs to rapid environmental change. Glob. Chang. Biol. 23, 2197-2205. doi: 10.1111/gcb.13639

Tye, P. D., Lajeunesse, T. C., and Christian, R. V. (2013). Long-range dispersal and high-latitude environments influence the population structure of a "stresstolerant” dinoflagellate endosymbiont. PLoS One 8:e79208. doi: 10.1371/ journal.pone.0079208

Van der Ven, R. M., Triest, L., De Ryck, D. J. R., Mwaura, J. M., Mohammed, M. S., and Kochzius, M. (2016). Population genetic structure of the stony coral Acropora tenuis shows high but variable connectivity in East Africa. J. Biogeogr. $43,510-519$.

Wang, S., Zhang, L., and Matz, M. (2009). Microsatellite characterization and marker development from public EST and WGS databases in the reef-building coral Acropora millepora (Cnidaria, Anthozoa, Scleractinia). J. Hered. 100, 329-337. doi: 10.1093/jhered/esn 100

Wei, F., Huang, W., Yu, K. F., Liao, Z., Wang, X., Wang, Y., et al. (2020). Embryonic and larval early development of Favia favus and Platygyra carnosus in the Weizhou Island, Guangxi. Haiyang Xuebao 42, 87-95.

Williams, D. E., Miller, M. W., and Baums, I. B. (2014). Cryptic changes in the genetic structure of a highly clonal coral population and the relationship with ecological performance. Coral Reefs 33, 595-606. doi: 10.1007/s00338-0141157-y

Wu, Q., Huang, W., Chen, B., Yang, E. G., Meng, L. Q., Chen, Y. M., et al. (2021). Genetic structure of Turbinaria peltata in the northern South China Sea suggest insufficient evolutionary potential of relatively high-latitude scleractinian corals to environment stress ScienceDirect. Sci. Total Environ. 775:145775. doi: 10.1016/j.scitotenv.2021. 145775

Xu, L. J., Yu, K. F., Li, S., Liu, G. H., Tao, S. C., Shi, Q., et al. (2017). Interseasonal and interspecies diversities of Symbiodinium density and effective photochemical efficiency in five dominant reef coral species from Luhuitou fringing reef, northern South China Sea. Coral Reefs 36, 477-487. doi: 10.1007/ s00338-016-1532-y

Yamano, H., Sugihara, K., and Nomura, K. (2011). Rapid poleward range expansion of tropical reef corals in response to rising sea surface temperatures. Geophys. Res. Lett. 38, 155-170.

Yang, X. D. (2013). Study of Gonad Development and Growths of Porites lutea, Goniopora djiboutiensis and Galxea fascicularis. Zhanjiang: Guangdong Ocean University.

Yu, J. K., Wang, H. Y., Lee, S. C., and Dai, C. F. (1999). Genetic structure of a scleractinian coral, Mycedium elephantotus, in Taiwan. Mar. Biol. 133, 21-28. doi: $10.1007 / \mathrm{s} 002270050438$

Yu, K. F. (2012). Coral reefs in the South China Sea: their responses to and records on past environmental changes. Sci. China Earth Sci. 55, 1217-1229. doi: $10.1007 / \mathrm{s} 11430-012-4449-5$

Conflict of Interest: The authors declare that the research was conducted in the absence of any commercial or financial relationships that could be construed as a potential conflict of interest.

Publisher's Note: All claims expressed in this article are solely those of the authors and do not necessarily represent those of their affiliated organizations, or those of the publisher, the editors and the reviewers. Any product that may be evaluated in this article, or claim that may be made by its manufacturer, is not guaranteed or endorsed by the publisher.

Copyright (c) 2022 Luo, Huang, Yu, Li, Chen, Huang and Qin. This is an openaccess article distributed under the terms of the Creative Commons Attribution License (CC BY). The use, distribution or reproduction in other forums is permitted, provided the original author(s) and the copyright owner(s) are credited and that the original publication in this journal is cited, in accordance with accepted academic practice. No use, distribution or reproduction is permitted which does not comply with these terms. 